\title{
Tecnologias de Informação e Comunicação: Contribuições para o Processo Interdisciplinar no Ensino Superior
}

\author{
The Contribution of Information and \\ Communication Technologies to Higher \\ Education according to an Interdiscipline \\ Proposal
}

Bernadete Malmegrim Vanzella Amem ${ }^{1}$ Lena Cardoso Nunes ${ }^{2}$

PALAVRAS-CHAVE:

- Comunicação Interdisciplinar;

- Tecnologia da Informação;

- Comunicação;

- Ensino Médico.

KEY-WORDS:

- Interdisciplinary

Communication;

- Communication

- Information Technology;

- Education, Medical.

Recebido em: 03/06/2005

Reencaminhado em: 08/08/2006

Aprovado em: 27/10/2006

\section{RESUMO}

Esta pesquisa teve por objetivo analisar como as Tecnologias da Informação e da Comunicação são utilizadas como possibilidade pedagógica para criar um ambiente de aprendizado e que contribuições podem trazer para a interdisciplinaridade prevista nas atuais diretrizes curriculares nacionais do ensino médico. A análise de dados enfatizou os seguintes temas: o projeto político-pedagógico no âmbito das diretrizes curriculares do ensino médico; as tecnologias de Informação e Comunicação no enfoque interdisciplinar; seus entraves na práxis pedagógica. As reflexões preliminares apontaram para os seguintes aspectos: a importância do projeto políticopedagógico como norteador dos objetivos do ensino; a integração interdisciplinar como um processo para a melhoria da qualidade do ensino; as TIC como um instrumento facilitador da aprendizagem; as dificuldades dos discentes frente à seleção de informações no ambiente virtual; e, finalmente, o desafio para a formação do médico generalista.

\begin{abstract}
The purpose of this study was to analyze the possibility of using Information and Communication Technologies as a pedagogical means for creating a learning environment and how these technologies could contribute to the interdisciplinary approach foreseen in the current national curriculum policies of medical education. Analysis of the data focused on the following topics: the political-pedagogical project in the context of the curriculum policies of the medical course; information and communication technologies from the viewpoint of interdisciplinarity and the difficulties they pose in the pedagogical praxis. A preliminary analysis pointed to the following aspects: the importance of the political-pedagogical project as a guideline for the teaching purposes; interdisciplinary integration as a process for a better teaching quality; the TIC as a learning facilitator; the difficulties of the students in selecting information from a virtual environment and finally, the challenge of forming general practitioners.
\end{abstract}




\section{INTRODUÇÃO}

O século 20 marcou a história como um período extremamente dinâmico e transformador. O homem não apenas alcançou a lua, como também temos hoje as informações em tempo real. Estamos vivendo numa era de transformações, uma era de interdependência global com a internacionalização da economia, nomeada por Tapscott ${ }^{1}$ de "Economia Digital", que se baseia no capital intelectual humano e nas redes, por meio das quais conhecimento e informação se transformam em meios de produção.

Os recursos tecnológicos de comunicação e informação estão presentes na vida cotidiana dos cidadãos e não podem ser ignorados, embora sua difusão ocorra de forma desigual. Hoje, os mais importantes fenômenos sociais, econômicos e culturais não acontecem isoladamente. O espaço geográfico é coberto por um denso emaranhado de redes por meio das quais transitam fluxos dos mais variados tipos, ocorrendo, assim, conexões entre os diversos lugares do planeta. Marshall Mcluhan, citado por Alves², lembra que o mundo se tornou uma aldeia global, referindo-se à globalização da cultura e das informações, criando novas exigências profissionais.

$\mathrm{O}$ avanço das TIC - Tecnologias de Informação e Comunicação - tem propiciado maiores possibilidades de disseminação de informações, facilitando o acesso a estas, mas é preciso desenvolver competências e habilidades num mesmo ritmo para se apropriar dos conhecimentos oferecidos pelas informações. È interessante registrar que são três os elementos básicos e mínimos da noção de informação: tradução possível em sinais, codificação possível desses sinais em dados e transmissibilidade dos mesmos. Se considerarmos somente essas características, todo tipo de linguagem contém e veicula informação. Talvez seja importante salvaguardar essa amplitude do conceito, mesmo porque hoje tendem a prevalecer como referência desse conceito a codificação/decodificação e a interconectividade eletrônica.

Vale ressaltar que:

“a geração de dados não estruturados não conduz automaticamente à criação de informação, e nem toda informação pode ser equiparada a conhecimento. Toda a informação pode ser classificada, analisada e refletida e processada de várias maneiras para gerar conhecimento"3.

No momento, esse novo modelo de comunicação com múltiplas fontes de informação demanda um novo cenário de aprendizagem que extravase a sala de aula, com um currículo que ultrapasse as fronteiras disciplinares.

Assim, no caso da educação superior não há somente que se adaptar às novas necessidades dessa sociedade, mas, prin- cipalmente, assumir um papel de ponta nesse processo. Para tanto, é necessário que os estudantes se apropriem de conhecimentos sociais, políticos, econômicos e culturais, numa perspectiva integrada, para que possam exercer uma prática profissional qualificada no ambiente em que estão inseridos. $\mathrm{O}$ ensino superior, se orientado nessa perspectiva, abre espaços para a compreensão de que o homem não está isolado, ao contrário, estabelece complexas relações de interdependência com o mundo. "O ser humano nos é revelado em sua complexidade: ser, ao mesmo tempo, totalmente biológico e totalmente cultural" 4 .

No entanto, os professores, no esforço de levar seus alunos a aprenderem, freqüentemente, dão maior importância ao conteúdo em si, desvinculado da realidade social, gerando a clássica dissociação entre teoria e prática, fato que pode ser observado nos recém-graduados do ensino superior. Assim, consideramos que a integração de conhecimentos e habilidades pode ser dificultada se as informações recebidas durante os cursos são dissociadas da prática pedagógica, sem um foco ao redor do qual se organize o conhecimento.

A sociedade atual sugere que o estudante seja alguém que busque construir seu conhecimento, alguém flexível, que saiba lidar com as necessidades de maneira criativa e que manifeste vontade de aprender, pesquisar e saber. Assim, precisamos envolver professores e alunos neste cenário e contextualizá-lo. Para isto, é importante pensar sobre um projeto pedagógico dos cursos superiores que contemple a perspectiva interdisciplinar e as TIC.

A legislação educacional brasileira em vigor, por meio das Diretrizes Curriculares Nacionais, aponta a exeqüibilidade em relação à estrutura e ao funcionamento da graduação. As diretrizes atuais, homologadas a partir de 2001, indicam a necessidade de estruturar os cursos por meio de um projeto pedagógico. O domínio das TIC também é recomendado ${ }^{5}$.

Nesse sentido, a presente pesquisa foi orientada com o objetivo de analisar as contribuições das Tecnologias da Informação e da Comunicação para o ensino médico, numa proposta interdisciplinar. Deste objetivo decorrem as seguintes questões: a) como as tecnologias digitais são utilizadas como possibilidade pedagógica para criar um ambiente de aprendizado colaborativo e b) que contribuições a internet pode trazer para a interdisciplinaridade prevista nas atuais diretrizes curriculares nacionais do ensino superior.

O contexto do ensino superior hoje, produto histórico da atividade humana, pode ser modificado, e sua transformação é realizada pelas ações concretas dos seres humanos. Daí a relevância em conhecer a atuação dos professores, os obstáculos na busca de uma nova práxis pedagógica e, por fim, 
oferecer indicações que norteiem a comunidade acadêmica para novas formas do saber no mundo contemporâneo. No momento em que estamos cuidando de questões relacionadas à aprendizagem, estamos também cuidando dos aspectos que preparam o indivíduo para a vida na coletividade, orientando-o para o pensamento ${ }^{6}$.

Nessa perspectiva, a sociedade contemporânea requer profissionais tecnicamente competentes, humanos, éticos, capazes de desenvolver ações no âmbito tanto individual como coletivo e em contextos situacionais diferentes, cujos saberes avançam pari passu com o desenvolvimento científico e tecnológico, desafiando professores, sociólogos, psicólogos, pedagogos, pesquisadores e planejadores, entre outros. Precisamos ter uma visão desta sociedade, na tentativa de buscar espaço para uma nova práxis pedagógica. Entende-se neste estudo por práxis a consciência crítica e reflexiva da prática na ação e sobre a ação - do ensino, no ambiente de ensinoaprendizagem, visando integrar o conteúdo teórico, a técnica, o contexto social. “É a compreensão da realidade humanosocial como unidade de produção e produto, de sujeito e objeto, de gênese e estrutura"7.

Sob esta ótica, seria inaceitável que "a arte de ensinar a ciência da vida" 8 não ousasse novas altitudes e novos rumos. A Medicina é ciência que cuida do bem-estar físico, psíquico e social, num meio ambiente equilibrado e sustentável, e não apenas uma técnica para diagnosticar e tratar uma patologia, e saúde é conservação da vida, e não ausência de doença. Para tanto, é necessário que o aprendiz detenha algum conhecimento sociocultural-antropológico, para assumir o exercício de uma abordagem integral e efetiva e uma prática profissional consciente.

Neste sentido, as análises contidas neste artigo podem contribuir para uma reflexão dos profissionais da área das ciências biológicas e saúde sobre o desenvolvimento de um perfil crítico, criativo, ético, reflexivo da área em foco, na urgência de prepará-los para os avanços contínuos da tecnociência, para as relações de trabalho e para as transformações sociais. Assim, poderão atuar como agentes transformadores do saber de modo amplo e global, com consciência da realidade social, aptos a se defrontar com os problemas de seu ambiente natural e cultural.

\section{A SOCIEDADE INFORMACIONAL E O ENSINO SUPERIOR}

Nas últimas décadas, presenciamos tanto o incremento de ocorrências desastrosas - como, por exemplo, o ataque terrorista de 11 de setembro em Nova York, aumento da pobreza mundial, deficiência energética, tráfico de drogas -, quanto uma grande expansão econômica, explosão das TIC, maior produção de bens sofisticados, além da descoberta do DNA humano.

Este panorama multifacetado aponta para a complexidade do real, pois agrega todos os aspectos nas dimensões intelectuais, religiosas, sociais e biológicas, ou seja, todos os fatos são interdependentes e interligados. Capra ${ }^{9}$ alerta que os principais problemas atuais são sistêmicos, portanto não podem ser entendidos no âmbito da metodologia fragmentada, característica de nossas disciplinas acadêmicas e de nossos organismos governamentais. Observa-se que os especialistas não estão preparados para explicar e/ou resolver os problemas referentes às suas áreas de atuação. Essa complexidade requer que reconheçamos os traços constitutivos, que não contêm apenas diversidade, desordem, mas também leis, ordem e organização9.

Todas estas transformações acabam por determinar mudanças sociais, políticas e culturais, dando maiores poderes sobre a nossa própria natureza e sobre o planeta. Estas alterações dependerão da utilização inteligente dessa tecnologia. Segundo Forester, ocorreu a "alteração da forma como os homens e as mulheres da Era Electrónica se vêem a si mesmos e no mundo" 10 .

A correlação entre conhecimento e eficiência está bem nítida nas organizações multinacionais que investem nas TIC para aumentar suas margens de lucro. Deste modo, a tecnologia move a revolução da informação: desenvolvida em função da lógica de acumulação capitalista e não de um projeto de integração social, reproduz um modelo já existente, tendo agora a informação como moeda e uma estratificação social determinada pelo conhecimento e não pela propriedade ${ }^{1}$.

Ressalta-se que, enquanto os países desenvolvidos investem nas TIC para manter a hegemonia, os países em desenvolvimento necessitam dessa tecnologia para reduzir o abismo que os separa do mundo desenvolvido. Independentemente de qualquer fator, um dos objetivos a alcançar é uma força de trabalho educada, capaz de interagir com as ferramentas informacionais e de desenvolver a Educação para a estabilidade e a coesão social.

A partir das TIC, estabeleceu-se uma cultura informacional, que proporciona um aumento da interação em tempo real, sem deslocamento físico, ou seja, simultaneidade e unicidade do espaço geográfico.

A sociedade se organiza em rede ${ }^{11}$; "a rede constitui um conjunto de nós interconectados", cujo instrumento básico é o computador individual conectado, fenômeno internacional que tem como 'carro-chefe' a internet, onde as redes informáticas favorecem a formação de indivíduos por descentraliza- 
ção de tarefas, dessincronização das atividades e a desmaterialização das trocas, além de potencializar a possibilidade de atores criativos, comunicantes, produtores e consumidores de novos instrumentos interativos, multiplicando os poderes e a eficácia de cada um. Esta sociedade é denominada 'Sociedade informacional" 12 .

A tendência é um aumento crescente da interação nos campos da educação, informação, lazer e trabalho, entre outros, permitindo que uma pessoa seja capaz de concorrer com empresas estabelecidas no mercado. Esse novo tipo de espaço, "ciberespaço", econômico, social, cultural e imaterial, permite um relacionamento não linear e multidimensional com uma dinâmica amplificadora. Este contexto cria uma nova cultura que hoje coexiste com a anterior ${ }^{12}$.

Nesse sentido, entende-se o valor da formação integrada a fim de que o especialista possa compreender e estar preparado para cooperar com outros especialistas, tanto da área das ciências biomédicas, como da área das ciências humanas e das ciências exatas, com as características de uma proposta interdisciplinar. Esta proposta supõe "uma atitude de superação de toda e qualquer visão fragmentada e/ou dicotômica que ainda mantemos de nós mesmos, do mundo e da realida$\mathrm{de}^{\prime \prime} 13$.

As TIC podem facilitar o processo interdisciplinar, pois apresentam uma série de vantagens em relação aos métodos convencionais de aprendizagem e facilitam a troca imediata de informações, a visualização de subtarefas como parte de tarefas mais globais, a adaptação da informação aos estilos individuais de aprendizagem, o encorajamento à exploração, maior e melhor organização das idéias, maior integração e interação, agilidade na recuperação da informação, maior poder de distribuição e comunicação nos mais variados contextos $^{14}$.

Na educação superior, mais precisamente na educação médica, observa-se a necessidade de propiciar aos jovens condições para se desenvolverem numa dimensão integrada do ponto de vista cognitivo, social, moral e ético. Isto contribuiria para formar indivíduos adultos capazes de uma boa prática profissional na sociedade e aptos para dirigir sua formação por valores e atitudes em relação à vida, ao ambiente, às relações humanas e a si próprios.

Os estudantes não estão isolados na escola; ao contrário, estabelecem complexas relações de interdependência dentro e fora dela. O entendimento dessas relações envolve a compreensão das condições físicas do meio, do modo de vida e da organização sociopolítica e cultural. Os estudantes devem construir seus conhecimentos por meio da interação com a realidade que os envolve. $\mathrm{O}$ conhecimento é dinâmico e não uma mera simplificação do conhecimento científico. O grau e a direção do desenvolvimento da consciência dependem, como sabemos, do ambiente cultural.

Em geral, no início de sua caminhada universitária, o estudante de Medicina é um adolescente e, no final, um adulto jovem, que nesse período conviveu com grandes mudanças internas, externas e físicas. A vida afetiva se afirma por meio da conquista de sua personalidade e integração à vida social dos adultos.

Contudo, é importante estar familiarizado com as TIC, que potencializam o aprendizado e a permanente atualização, sem nos esquecer do contexto social e da diversidade cultural. Uma questão significativa é rever a obrigação da universidade na formação profissional, com responsabilidade social e compromisso com a cidadania. As práticas que não identificam esses aspectos podem criar distorções para a solução dos problemas. Cabe à educação superior, por meio das atividades curriculares, promover um indivíduo consciente, crítico, criativo e reflexivo. Capra9 ${ }^{9}$ denuncia:

“Os estudantes não são encorajados a desenvolver conceitos integrativos, e as instituições de pesquisa dirigem suas verbas quase que exclusivamente para a solução de problemas formulados no âmbito dos conceitos cartesianos. Os fenômenos biológicos que não podem ser explicados em termos reducionistas são considerados indignos de investigação científica. Os problemas que não se pode resolver hoje, ao que parece em virtude de sua abordagem estreita e fragmentada, estão todos relacionados com a função dos sistemas vivos como totalidade e com suas interações com o meio ambiente" ${ }^{\prime}$.

A questão interdisciplinar nos projetos pedagógicos do ensino superior

Os progressos científicos e tecnológicos e as transformações sociais exigem uma visão do futuro no sentido de colaborar para a formação de profissionais aptos para atuar num mundo globalizado. O século 21 demanda que as instituições educacionais busquem a compreensão do que seja o homem, o mundo e o que o homem representa neste mundo, ou seja, mergulhar na idéia de que o mundo é construído por nós, num processo incessante e interativo, e nos remete à reflexão de como habilitar os jovens universitários para o amanhã.

Sob este prisma, a universidade consciente de seu papel necessita redefinir princípios, fundamentos e procedimentos em relação à educação superior. Para corroborar estas transformações, as Diretrizes Curriculares definidas pelo Conselho Nacional de Educação eliminam as amarras de um currículo pleno, fechado em verdadeiras grades e padronizado 
para todo o território nacional. E propõem um modelo curricular mais flexível, integrado e sistêmico, que contemple os conhecimentos, habilidades e atitudes de forma mais ampla, permitindo a modernização dos projetos pedagógicos, da estrutura e do funcionamento dos cursos em bases interdisciplinares. Assim, as universidades adquiriram mais autonomia no planejamento, na organização e na gestão de suas atividades-fim, por meio dos projetos pedagógicos de seus cursos com perfis que atendam às exigências da sociedade atual.

Vale ressaltar a lendária frase de Pascal citada por Morin ${ }^{6}$ : "é impossível conhecer as partes sem conhecer o todo, como é impossível conhecer o todo sem conhecer as partes". Assim, é preciso conhecer os fenômenos em sua totalidade em vez de recortá-los e separá-los. Há problemas que só são solucionados por meio de uma busca interdisciplinar. Deste modo, o especialista está perdendo espaço para o generalista, que detém conhecimentos específicos e gerais que podem preparálo para lidar com situações diversas, complexas e inesperadas valendo-se, além dos conhecimentos científicos necessários a sua formação, de habilidades cognitivas outras que lhe permitem tomar decisões nos mais variados ramos. Para tanto, é preciso um novo tipo de formação intelectual, que facilite a visão do contexto em que hoje o conhecimento se aplica. Espera-se que a qualificação de natureza geral e abstrata seja a base para os conhecimentos específicos e que também constitua a principal fonte de competência na interação profissional e em atividades complexas.

Desse modo, a proposta para a formação do generalista no ensino superior sempre foi encarada como comprometedora da tão almejada "formação científica do profissional", não se estabelecendo uma distinção entre a importância da formação geral na graduação e a formação do profissional geral ou generalista. Na verdade, a formação do profissional generalista sempre foi considerada muito difícil de alcançar, e para tanto haveria que se estender o curso para além dos anos regulamentares.

Arendt $\mathrm{t}^{15}$ nos alerta que a validade de uma doutrina é determinada por seu bom êxito prático. As teorias modernas em relação à aprendizagem têm como um dos pressupostos básicos a idéia de que só é possível conhecer e compreender aquilo que nós fazemos, o que consiste, na medida do possível, no aprender fazendo.

Assim, a educação está passando por um significativo momento de reflexão diante do impacto ditado pelos recentes fundamentos e diretrizes curriculares, sugerindo novos paradigmas na organização e gestão dos projetos pedagógicos para a educação superior. Isto para atender à demanda do acelerado desenvolvimento científico, tecnológico, econômi- co e cultural, que requer a formação de um profissional com postura crítica e criativa, e o despertar permanente de competências adequadas às exigências atuais. A sociedade exige, cada vez mais, um inter-relacionamento efetivo na cadeia do conhecimento, requerendo da instituição de ensino superior uma postura inovadora e ajustada às suas necessidades. Essas mesmas Diretrizes Curriculares recomendam conferir maior autonomia às instituições de ensino superior na definição de currículos, a partir da explicitação das competências e habilidades que o aluno deve desenvolver, por meio da organização de um projeto pedagógico flexível e capaz de se adaptar à dinâmica das demandas dessa sociedade do conhecimento, buscando a inovação e a qualidade do ensino de graduação.

Veiga $^{16}$ alerta que a construção do projeto pedagógico passa pela relativa autonomia da escola e de sua capacidade de delinear sua própria identidade. Isto significa que a escola deve ser um lugar de debate e diálogo fundado na reflexão coletiva. Assim, "todos deverão definir o tipo de sociedade e o tipo de cidadão que pretendem formar"16.

Nessa ótica, o projeto pedagógico constitui um trajeto a ser construído com a participação de todos, estabelecendo relações, superando obstáculos, apontando correções e vislumbrando pistas para a melhoria contínua. Ele envolve a clara definição do ponto aonde se pretende chegar; fornece uma direção; orienta o caminhar da ação docente, discente e dos gestores da instituição. Sugere não esquecer a importância do resgate dos valores sociais e culturais, o exercício de novas posturas e a adoção de novas práticas pedagógicas. Nele estão implícitas também: a prática docente, a flexibilidade na execução de trabalhos interdisciplinares e uma visão sistêmica e globalizada. Em outras palavras, ele fornece os instrumentos que definem o caminho e as ações a serem desenvolvidas, de maneira interativa e com uma proposta curricular integradora e flexível ${ }^{17,18}$.

\section{PROCEDIMENTOS METODOLÓGICOS}

A presente pesquisa buscou assumir as características da investigação qualitativa, assim enumeradas de acordo com Bogdan 19: (a) a fonte direta da coleta de dados é o ambiente natural, constituindo o investigador o principal instrumento; (b) a investigação qualitativa é descritiva, isto é, os dados coletados são em forma de palavras, sendo que os resultados escritos incluem as transcrições de entrevistas e as notas de campo, entre outros; (c) na pesquisa qualitativa, o interesse é maior pelo processo que pelo produto, o que tem sido significativamente útil na investigação educacional, no registro da história natural da atividade que se pretende investigar, no local onde as referidas atividades ocorrem; (d) a análise dos 
dados nesse tipo de pesquisa é indutiva, isto é, à medida que os dados são coletados e agrupados, as abstrações são construídas; (e) "o significado é de importância vital na abordagem qualitativa"; nesse sentido, o que importa são as perspectivas dos participantes.

\section{Resultados do estudo}

Este artigo resultou de um estudo realizado numa instituição privada, no curso de graduação de Medicina. Os participantes deste estudo foram os coordenadores do curso e das disciplinas e professores (membros e não membros do colegiado). Na análise dos dados relativos às entrevistas, tendo em vista os procedimentos antes explicitados e de acordo com as etapas da análise temática proposta por Bardin ${ }^{20}$, emergiram três temas e seis subtemas:

1 - Projeto político-pedagógico no âmbito das diretrizes curriculares do ensino médico;

1.1 - a postura do professor para a formação de um profissional generalista;

1.2 - vantagens e desafios do projeto político-pedagógico;

2 - As Tecnologias de Informação e Comunicação em um enfoque interdisciplinar;

2.1 - a mudança do papel do professor;

2.2 - a importância do trabalho coletivo;

3 - Entraves na práxis pedagógica;

3.1 - entraves à interdisciplinaridade;

3.2 - entraves às Tecnologias de Informação e Comunicação.

O primeiro tema enfatizou as Diretrizes Curriculares que preconizam o projeto político-pedagógico para a formação de um médico generalista; neste cenário, emergiram dois subtemas: postura do professor de Medicina no momento atual para a formação de um profissional com uma visão ampla de saúde, e vantagens e desafios desse projeto.

Quanto ao subtema 1.1, a análise das entrevistas mostrou pontos de convergência entre os professores entrevistados; eles identificam com clareza suas responsabilidades na formação de médicos mais conscientes e mostram grande preocupação no resgate dos valores e da ética profissional. Abaixo, é transcrito um trecho de entrevista que aponta esse subtema:

P6: (...) no que diz respeito à mudança da postura dos professores no sentido da transformação da formação de médicos mais conscientes do seu papel profissional num sistema de saúde baseado nos direitos de cidadania da população, na necessidade de uma abordagem ampliada do processo saúde-doença (...)

A sociedade atual exerce considerável pressão para que se ultrapassem os atuais conceitos mecanicistas da Medicina e se desenvolva um enfoque mais holístico da saúde. Capra ${ }^{9}$ observa que o amplo conceito de saúde, necessário à nossa transformação cultural, é "um conceito que inclui dimensões individuais, sociais e ecológicas, exige uma visão sistêmica dos organismos vivos e, correspondentemente, uma visão sistêmica de saúde".

Arendt ${ }^{15}$ alerta que o educador é um dos representantes dos jovens em um mundo que estes irão assumir; essa responsabilidade está implícita no fato de que os jovens são introduzidos pelos adultos em um mundo em contínua transição.

P5: Os nossos alunos têm atividade desde o $1^{\mathrm{o}}$ semestre, em cima de problemas importantes na análise do curso no Brasil hoje, com uma carga horária de prática grande, desde o início, e um currículo que impõe, vamos dizer assim, uma integração transversal do $1^{\circ}$ período ao $12^{\circ}$, porque temos algumas atividades que envolvem os alunos e professores dos diversos períodos.

Para Morin 5 , a importância da prática está relacionada ao aprendizado, pois "o conhecimento de toda organização biológica exige o conhecimento de suas interações com seu ecossistema". Neste sentido, Capra ${ }^{9}$ o reafirma quando diz: "os mundos interior e exterior estão sempre interligados no funcionamento do organismo humano; eles interagem e evoluem juntos". O encadeamento entre a experiência prática e o conhecimento teórico pode ser englobado no aforismo citado por Maturana21: "todo fazer é um conhecer e todo conhecer é um fazer".

O subtema 1.2 reúne as falas dos participantes relacionadas às vantagens e aos desafios do projeto político-pedagógico. Nos depoimentos sobre as vantagens, observamos que a totalidade dos professores entrevistados tem consciência plena de que o projeto pedagógico é um processo, está no dia-adia dos docentes e, por ser construído coletivamente, facilita a interação entre os professores; também percebem a característica inovadora em relação à potencialidade para a formação de um médico generalista, com ênfase no eixo saúde da família, valorizando a formação humanista e ética como um promotor da saúde integral do ser humano. A seguir, apresentamos uma das falas relacionadas às vantagens consideradas relevantes:

P3: (...) eu acho isso um avanço bastante grande, dentro do olhar que ele pode ter no primeiro período e isto vai 
num crescendo até ele conseguir articular isto ao atendimento dele no PSF, no internato. Isto é um grande avanço do currículo da escola.

Um dos desafios que as Diretrizes Curriculares trazem para as escolas médicas nesse processo é a montagem coletiva do projeto pedagógico, centrado no aluno como sujeito de aprendizagem e tendo o professor como facilitador. Com muita clareza, P7 elucida os desafios deste projeto: ser inovador; ser colocado em prática; apontar para a formação de um "novo" profissional; e estar inserido no contexto mais amplo da sociedade civil e política:

P7: Vejo o projeto como sendo um grande desafio, na medida em que aponta para uma nova visão de ensino. (...) A preocupação com a integração entre disciplinas e períodos, a participação dos docentes e uma visão ampla do conceito de saúde são características marcantes do projeto.

O projeto político-pedagógico é justamente um instrumento teórico-metodológico que visa enfrentar os desafios do cotidiano do curso, só que de uma forma consciente, sistematizada, orgânica, científica e - o que é essencial - participativa, por meio de uma visão interdisciplinar, que reflita sobre valores e construa conhecimentos das diferentes áreas do saber. O mais importante é realizar um projeto político-pedagógico voltado para o futuro sem dar as costas ao passado. Um instrumento de transformação da realidade, que ajude a organizar e expressar o que se deseja e o que foi feito, ou seja, tomar consciência e tentar diminuir a distância entre ambos.

O segundo tema emergente das falas dos participantes abordou as TIC num enfoque interdisciplinar. Neste tema, há uma coerência em relação ao enfoque interdisciplinar e suas multipossibilidades, facilitadas ou não pelas TIC, na busca da formação de um profissional médico mais completo para atender as necessidades da medicina contemporânea, que contemple a valorização dos aspectos epidemiológicos, sociais, psicológicos e culturais nas doenças e nos doentes. O conjunto dos depoimentos apresentados neste tema deu origem a dois subtemas: a mudança do papel do professor e a importância do trabalho coletivo.

Em relação à mudança do papel do professor, observa-se a capacidade crítica e reflexiva quanto à mudança na relação pedagógica, no "aprender a aprender" e na prática interdisciplinar, facilitados pelas TIC:

P2: Eu acho que as tecnologias favorecem, mas tem que ter o lado do professor, que tem que se modificar. O professor no modo presencial, mas assim, como experiência, como vivência, e como seleção do que é melhor e do que é pior, não só simplesmente blá blá blá. Em relação à pesquisa, ela é ótima. Então o papel do professor mudou neste sentido (...). Uma vez que ela chegou e chegou trazendo toda essa bagagem de informações, isso fez com que mudasse o nosso raciocínio do que é ensinar. (...) eu acho que aprofundou mais o que é ensinar, ensinar não é mais simplesmente mandar ou transmitir aquela informação, não precisa da gente mais pra isso, precisa pra orientar como chegar na informação e eles sabem lidar com a tecnologia melhor que a gente (...).

A maioria dos docentes relata a aproximação do ensino, da pesquisa e dos serviços de saúde como atividades que se inter-relacionam em consonância com o trabalho e com a necessidade de uma atualização constante. Desta maneira, a internet pode proporcionar o acesso aos conhecimentos, permitindo ao professor abandonar o papel de transmissor de informação para desempenhar o de guia e conselheiro para o estudante. O essencial da conduta educativa não se situa, portanto, do lado da transmissão de informação, mas do lado da construção de sentido com os aprendizes.

No subtema 2.2 - a importância do trabalho coletivo -, os docentes enfatizaram os seminários, o trabalho em equipe, a interdependência com a instituição e com a coordenação do curso. Também mostraram um forte ponto de convergência em relação à necessidade de atualização permanente, a preocupação com a aprendizagem e a importância da integração entre as disciplinas, que se realiza de vários modos complementares.

A interdisciplinaridade contribui para que as pessoas "sintam-se partícipes de uma equipe, com metas comuns a serem encaradas de maneira cooperativa, e responsáveis frente aos demais em suas tomadas de decisões" ${ }^{22}$. É preciso insistir no papel da negociação entre todas as pessoas que compõem a equipe, proporcionando esclarecimentos, debatendo questões metodológicas, conceituais e ideológicas para se avançar na resolução de problemas ou tópicos. Só assim serão esclarecidas as informações, perspectivas e posições daqueles que estão fazendo o trabalho. A seguir, P3 pontua, de forma abrangente, esse aspecto:

P3: Os seminários, por exemplo, de um estudo de caso com a presença dos alunos e professores das diversas áreas, presentes na sala debatendo... eu acho que acabo aprendendo mais que os próprios alunos ouvindo os próprios alunos e colegas... problematizando o assunto apresentado então aprende-se bastante também neste processo, nós professores temos que estudar para poder participar da atividade, isto é bastante positivo. 
O exercício interdisciplinar na prática cotidiana exige, portanto, encontros, trabalhos e/ou contatos entre grupos de professores, e entre professores e alunos. Na sociedade contemporânea, a atualização é uma necessidade de todos os profissionais, uma vez que também propicia o desenvolvimento profissional dos professores, articulado com as escolas e seus projetos.

O último tema - entraves na práxis pedagógica - proporcionou aos participantes identificar vários obstáculos em relação à práxis pedagógica no cotidiano escolar. Esse tema abrange dois subtemas: entraves ao processo interdisciplinar e dificuldades das TIC na aprendizagem.

Em relação ao primeiro subtema - entraves à interdisciplinaridade -, os professores ilustram as dificuldades enfrentadas em busca do bom andamento do processo interdisciplinar, dado seu caráter inovador, que se manifesta no contexto das vivências, experiências e necessidades no âmbito do curso. Nunes ${ }^{17}$ ressalta que um dos desafios mais complexos é “dar continuidade ao processo, não desistir, diante dos inúmeros entraves que a cada encontro se apresentam. A persistência dos que estão à frente e a conquista de parceiros para essa difícil aventura são a meta que vai nortear o grupo".

A fala que se segue destaca os principais obstáculos percebidos pelos professores: a formação profissional dos docentes, a expectativa dos discentes para a especialização, a resistência destes como sujeitos ativos da aprendizagem e a carga horária dos professores. $\mathrm{O}$ trecho da entrevista a seguir resume genericamente as entrevistas como um todo:

P1: O desafio maior é o de conseguir na prática a interação entre ensino, pesquisa, assistência, trabalho de campo, estrutura física adequada com recursos disponíveis. $\mathrm{O}$ entendimento deste projeto pedagógico nem sempre é compreendido, tanto pelo aluno quanto pelo professor. Há uma certa resistência por ser de difícil execução e por ser diferente do usual. Requer um grande esforço conjunto; geralmente o que depende de muitas variáveis costuma ser mais lento do que se deseja na prática.

A integração interdisciplinar constitui um desafio nunca alcançado por completo e por isso permanentemente buscado. Não é apenas uma proposta teórica, mas, sobretudo, uma prática. A busca da perfeição é realizada na prática; na medida em que são feitas experiências reais de trabalho em equipe, exercitam-se suas possibilidades, problemas e limitações.

$\mathrm{O}$ último subtema - entraves às Tecnologias de Informação e Comunicação - reflete os entraves observados na utilização das TIC em relação tanto à infra-estrutura e recursos no ensino médico, quanto às próprias linguagens digitais e à utilização da tecnologia como complemento na clínica médica.
No que tange ao processo de ensino-aprendizagem, quase a totalidade dos professores se refere à dificuldade do corpo discente em se posicionar criticamente frente à quantidade e diversidade de informações oferecidas na internet. Também há algumas reflexões sobre a substituição da relação médicopaciente pela velocidade da informação ou em detrimento dos exames complementares:

P3:(...) agora o lado negativo é que as pessoas estão perdendo o hábito da leitura, eu acho salutar as pessoas freqüentarem uma biblioteca. (...) A própria linguagem na internet é uma linguagem diferenciada, então assim, está trazendo problemas, eles estão sentindo dificuldades.(...) e uma outra coisa, em relação à tecnologia temos que tomar um certo cuidado porque a prática clínica, aquela coisa que a gente tem na relação com o paciente, de conversar, de entender um pouco a história de vida das pessoas, o aspecto socioeconômico, esse ritmo da internet e de todos esses meios faz com que o aluno acabe incorporando isso, então perde um pouco aquele aspecto da clínica, da relação médico-paciente, principalmente do contato mais próximo.(...) Eu acho que é isto, substituir o exame complementar que deveria ser complementar e passa a não ser complementar (...) eu acho que ele perde um pouco da subjetividade da relação com o paciente. A relação com o paciente acaba ficando prejudicada, porque ele acaba substituindo a velocidade para se fazer o diagnóstico, seja pela imagem. (...) É eles dominam, mas acabam por não saber selecionar, acho que eles não sabem selecionar.

Nesta entrevista, observa-se que os estudantes devem conhecer todos os recursos tecnológicos disponíveis para saber quando e como não usá-los. Além disso, pela facilidade de acesso aos equipamentos de alta tecnologia, deve-se conscientizar os estudantes de que estes são produto de um complexo industrial de grande poderio; daí o risco de que, usando "técnicas de promoção mercadológica, seja possível induzir a conflitos com o exercício ético da profissão, com afrouxamento dos padrões do comportamento". A transcrição acima também revela a preocupação do professor em relação ao exame complementar. Os testes de laboratório e a medição de parâmetros físicos na sala de exames não devem ser mais importantes para o diagnóstico do que a avaliação do estado emocional, da história familiar ou da situação social do paciente9.

Um dos desafios da inovação passa inevitavelmente pelo mundo da eletrônica, sobretudo da informática. O que mais sobressai neste particular é a disponibilidade de informações. Assim, o ensino não se sustenta mais com aulas expositivas, e, 
ao mesmo tempo, cabe ao professor esclarecer o "lugar" da informática na aprendizagem. "Temos muito mais o problema de naufragar diante do acúmulo excessivo de informações, assim como da seletividade destas"18.

\section{CONSIDERAÇÕES FINAIS}

No inicio deste novo século, vivenciamos transformações que acabam por determinar mudanças sociais, políticas e culturais, com crescimento excessivo das cidades, das instituições sociais e das inovações tecnológicas. Diariamente, estas bombardeiam nossas mentes com milhões de informações, configurando uma complexidade que parece ser negativa (pois gera incerteza); contudo, essas inovações implicam o desafio de entendermos que o nosso pensamento é complexo, Morin 4 : "que se esforça por unir, não na confusão, mas operando diferenciações. (...) o que é vital, principalmente na vida cotidiana, (...), pois, espontaneamente tentamos contextualizar". (p. 33)

Neste cenário, buscamos entender quais as possibilidades práticas de tentar conseguir nos dias de hoje uma visão holística de saúde para os futuros profissionais médicos.

Nos relatos dos professores, foi possível perceber que eles identificam a importância do trabalho coletivo e do aprendizado colaborativo, além de identificarem as TIC como um instrumento facilitador da aprendizagem. No campo da educação, de acordo com os participantes, a interdisciplinaridade constitui condição para a melhoria da qualidade do ensino, mediante a superação contínua da sua já clássica fragmentação, uma vez que orienta a formação global do homem.

A questão da contribuição da internet foi evidenciada nas respostas dos professores, que, de um lado, destacam o valor da internet para a pesquisa em um mundo globalizado, mas, de outro lado, apontam as dificuldades dos alunos em selecionar as informações mais coerentes e pertinentes aos trabalhos desenvolvidos no decorrer do curso, assim como em "deletar" a quantidade de "lixo" encontrado no ambiente digital. Outra constatação foi a percepção da necessidade do projeto político-pedagógico como norteador dos objetivos a serem atingidos.

Embora preocupados com a formação do médico generalista, chama a atenção o desafio diante do novo e a responsabilidade em relação à postura ética, ao compromisso com a aprendizagem dos alunos e à inserção destes no mundo atual.

Também foi enfatizada a importância dos seminários, encontro entre professores e alunos, e suas relações com a produção do saber, que, além de propiciarem uma costura entre conhecimento, sentimento e atuação de cada um e do grupo como um todo, possibilitam a reflexão e o "aprender a aprender", configurando o aprendizado colaborativo.
Mais um importante ponto de convergência foi aqui observado: todos os professores percebem o desafio atual para a formação do médico generalista e a dificuldade dos discentes frente a esse novo paradigma, já que eles chegam à faculdade influenciados pela família, educação e ambiente sociocultural.

Parece que não há receitas para a construção interdisciplinar, é um processo de intercomunicação entre os professores com encontros e desencontros, avanços e recuos. A implantação é um processo difícil, ocorrem resistências de ordem institucional, psicossocial e epistemológica ${ }^{17}$.

Algumas possibilidades podem ser delineadas tendo por base as considerações elaboradas neste estudo. Embora não se configurem como definitivas, podem ser úteis na visualização e entendimento da complexidade da formação do médico generalista. Pode-se destacar a possibilidade da instituição como parceira, com o compromisso de proporcionar espaços de interação em que professores e alunos não apenas partilhem suas experiências, mas também possam elaborar uma reflexão crítica sobre sua prática e, desse modo, promover o autoconhecimento e a autoformação por meio de um debate freqüente do processo de ensino-aprendizagem.

Este artigo teve a intenção de mostrar algumas possibilidades delineadas e pretendeu instigar o debate, a compreensão e a reflexão acerca desse processo complexo de construção do conhecimento para a formação de um perfil médico baseado na formação geral e orientado às necessidades de saúde da população, como formulado nas diretrizes nacionais para o ensino médico. Pretendeu, também, estimular a busca de trajetórias orientadoras para uma prática médica compatível com as necessidades deste novo milênio.

\section{REFERÊNCIAS}

1. Tapscott D. Geração digital: a crescente e irreversível ascensão da_geração net. São Paulo: Makron Books;1999.

2. Alves L., Nova C., orgs. Educação e tecnologia: trilhando caminhos. Salvador: UNEB; 2003.

3. Assmann E. H. Reencantar a educação: rumo à sociedade aprendente. Petrópolis: Vozes; 1999.

4. Morin E. A cabeça bem feita: repensar a reforma, reformar o pensamento. 3. ed. Rio de Janeiro: Cortez Editora; 2001.

5. Morin E. Ciência com consciência. 6 ed. Rio de Janeiro: Bertrand; 2002

6. Brasil. MEC. Secretaria de Educação Superior. Diretrizes Curriculares Nacionais para os Cursos de Graduação, com fundamento no Parecer Sesu [2004]. Disponível em: http:/ /www.mec.gov.br/Sesu/diretriz.shtm . 
7. Kosik, K. Dialética do concreto. 2ed. Rio de Janeiro: Paz e Terra;1976.

8. Amy, K. Entrevista.Boletim ABEM.2004;4.

9. Capra, F O Ponto de mutação. 28 ed. São Paulo: Cultrix; 2002.

10. Forester, T. Informática e sociedade, evolução ou revolução? Lisboa: Salamandra;1985

11. Castells, M. A sociedade em rede. 6 ed.São Paulo: Paz e Terra;2003.

12. Rosnay, J. O salto do milênio. In:Martins, FM; Silva, J.da S. Para navegar no Século XXI: tecnologias do Imaginário e Cibercultura. Porto Alegre: Sulina/Edipucrs; 2000.

13. Bochniak, R. Questionar o conhecimento: interdisciplinaridade na escola. In: Queluz, A G. (org.) Interdisciplinaridade: formação de profissionais da Educação. São Paulo: Pioneira, 2000.

14. Perrenoud, P. Dez novas competências para ensinar.Porto Alegre: Artmed Editora; 2000.

15. Arendt, H. Entre o passado e o futuro. São Paulo: Perspectiva; 1979.

16. Veiga, I. P. org. Projeto político-pedagógico da escola: uma construção Possível. 9 ed, Campinas: Papirus;2001.
17. Nunes, L. C A Interdisciplinaridade nos projetos pedagógicos do ensino superior. [mensagem pessoal]. Recebida por<pebes@uol.com.br>. Acesso em:13 de maio de 2002.

18. Demo, P. Desafios modernos da mducação. 11 ed. Petrópolis: Vozes; 2001

19. Bogdan, R. \& Biktlen, S. Investigação qualitativa em educação. Porto: Porto Editora;1999.

20. Bardin, L. Análise de conteúdo.Lisboa: Edições 70; 1977

21. Maturana, H. R; Varela F. J. A árvore do conhecimento: as bases biológicas da compreensão humana. São Paulo: Palas Athena; 2001.

22. Santomé, J. T. Globalização e interdisciplinaridade, o currículo integrado. Porto Alegre: Artmed; 1998.

\section{Conflito de Interesse}

Declarou não haver.

\section{Endereço para correspondência}

Bernadete Malmegrim Vanella Amem

Rua Gastão Rocha, 26/201 - Icaraí - Niterói

24220-100 Rio de Janeiro

e-mail: pebe@uol.com.br 